\title{
Evolution of the Development Impact Bond (DIB) in the International Markets: A Results-Based Approach to Development Finance
}

Christopher Egerton-Warburton(Lion's Head Global Partners Director)

\section{Contents}

I. Introduction

II. Development of the DIB Market

III. Current State of the Development Impact Bond Market

IV. The Future of Development Impact Bonds

\section{Introduction}

The Development Impact Bond (DIB) market is still in its infancy. The term was only coined in 2012 by the Centre for Global Development DIB Working Group and the first transaction was executed for a total of US\$238,000 in June 20141).

However as a concept, international finance has utilized "bonds" (financing) for "development" to achieve "impact" since the inception of international aid.

1) The inaugural DIB was a three-year pilot project investing in Educate Girls, an NGO that works in public schools in Rajasthan. The Children's Investment Fund Foundation (CIFF) was the outcome payer. 
Many investors would argue that the early capital markets transactions of countries like Hungary, South Africa and Mexico were in their own way "impact" investments. They were all intended to help finance the economic development of the respective borrowing countries. The link was even more direct in countries like Korea and Brazil where the primary borrower on the international capital markets were domestic development banks such as Korea Development Bank (KDB) and BNDES in Brazil, respectively.

In this paper we seek to describe the background to the Foreign DIB Market to provide some context to its evolution, the current status of the Foreign DIB market and to give some perspectives on potential future developments in this dynamic sector.

Using financial instruments to encourage development of the world's least-developed nations is a concept that can be traced back to the Marshall Plan post World War II. Subsequently, the Bretton Woods Institutions arguably were the first adopters of applying "innovative financing" for development. The World Bank Group and the International Monetary Fund would argue that they have been issuing "development impact bonds" for over 60 years. Many countries also have their own international development finance institutions (DFIs) some of whom also finance themselves in the capital markets such as KfW of Germany, FMO (Netherlands Development Finance Company) and AFD (Agence France de Development).

The differentiating point between historic government aid for development and new instruments of innovative finance lies in the crux of risk transfer between stakeholders. At one extreme, an investor in a loan of $\mathrm{KfW}, \mathrm{FMO}$ or AFD is taking pure Sovereign risk of the host nation. The issuers are fully guaranteed by their governments, meaning that they are highly rated and will trade at a yield comparable to Government securities. These organisations can create great 
impact because they are not expected to have the same risk/return balance for their shareholder (Government) as would be expected by the shareholders of a commercial bank. By offering a lower cost of capital to highly impactful projects, they are able to drive economic development.

The multilateral development banks (MDBs) work on a similar basis, only here they replace the direct sovereign guarantees of the DFI's with a mix of paid in and callable capital to secure top ratings. The MDBs are viewed as some of the lowest risk borrowers in the capital markets and their debt are a staple of Central Banks and Sovereign Wealth Funds (SWFs) seeking a "safe" investment. Therefore with a very low cost of capital they are able to profitably on-lend those funds to developing country nations at a cost substantially below the cost of debt that would be incurred if the developing country were to borrow directly from the public markets themselves.

\section{제 I장}

제I장

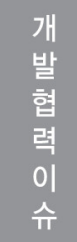

제 III장

Over the past 10 years, we have witnessed two key developments that have driven the development of the DIB:

- An increasing interest in results based financing, the largest example of which is arguably the Carbon Market;

- A willingness by donors and other parties to "buy down" debt if certain results are achieved

It can be seen that if a lender is inserted into the frame, to lend with the expectation that a loan will be bought down if a result is achieved a development impact bond has been created. The rise of the concept of an impact investor has generated a pool of capital to serve as the necessary lender in such a circumstance. 
$<$ Chart 1> Evolution of the Development Impact Bond

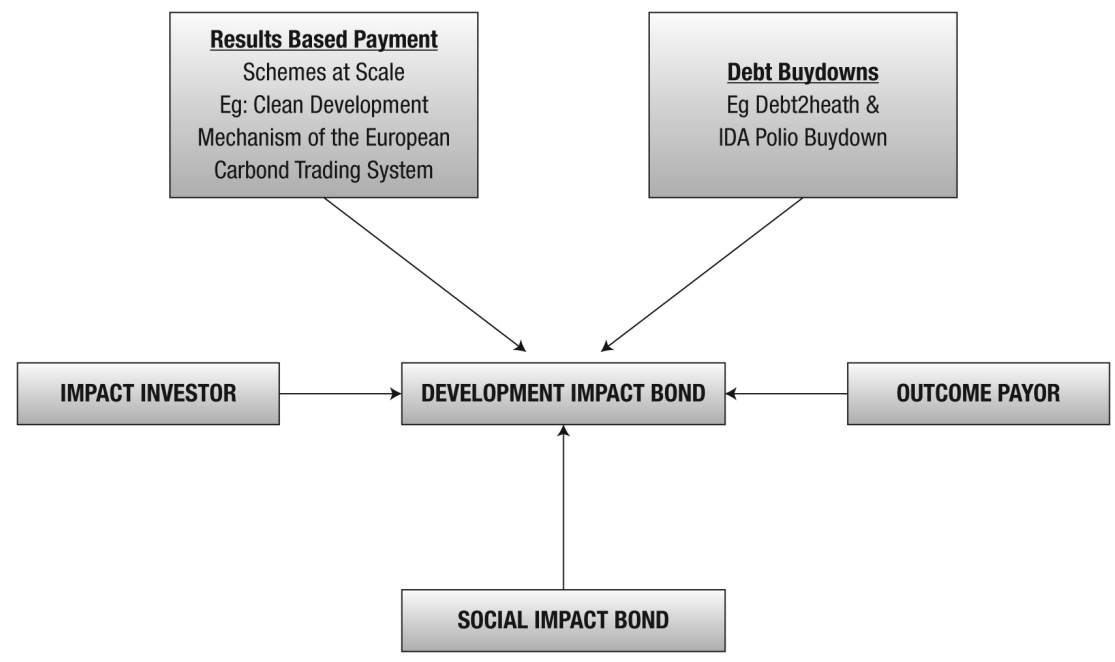

It is important to recognize that the rules of finance have not been re-written and DIBs like all other investments must provide a measurable and predicable risk return. The return may come from a variety of sources, not necessarily the project itself, but the return must be there. This is an important distinction, because if a DIB is simply a form of repackaged philanthropy, where a loss is expected, then it will never scale, indeed it could be argued that it is simply adding friction to a system that already work just as well with grants. Philanthropic donors may make the case that by defining the results clearly upfront, a positive outcome is more likely to occur, but this issue could be resolved without resorting to a DIB, through improved project design and procurement.

The fundamental concepts of results-based financing and supporting economic development through capital investment that underlie "DIBs" and "Impact Investing" are not new. This is advantageous for the development of DIBs in practice because it ensures that lessons of the past are incorporated into the future design. Furthermore, there are historic examples of results-based aid at 
large scale. Reaching scale is critical because for DIBs to succeed they need to seek to achieve a quantum step forward in the scale of what has been achieved in the past (and not a downward step in scale). We believe this can be achieved by recognizing and building on established models. We would note that the sector is under rapid development at this point in time and so the ultimate path taken may differ significantly from that being pursued at present.

\section{Development of the DIB Market}

제 I장

제I장

"If I have seen further, it is by standing on the shoulders of giants" Isacc Newton 1676

The DIB concept was first defined in 2012 by the Developing Impact Bond Working Group. While the Development Impact Bond (DIB) is generally described as a derivative of its nomenclature cousin - the Social Impact Bond (SIB), the concepts behind DIBs, of outcomes-based contracting, and the financing it necessitates, have been around for a long time. In 2010 the Centre of Global Development of Washington DC coined the phrase Cash on Delivery AID (COD)2). Since that time there has been keen interest from the donor community to promote the concept of "Results Based Finance" (RBF) and the literature is full of pilots and case studies of RBF projects. The learnings from these are important as they directly relate to DIBs and therefore it is critical that DIBs build on areas which have been shown to work for CDO or RBF structures and not to reinvent the wheel.

Like its cousin, the SIB, the DIB has a mandate to facilitate risk transfer between vested stakeholders in the social outcome. It actives a group of risk-taking investors and links measureable activities to the outcomes risk payor. The DIB working group of which the author was a member, defined the 2) Birdsall \& Savedoff (2010), Cash on Delivery: A New Approach to Foreign Aid 
distinction between a DIB vs a SIB as the difference in the nationality of the outcome payor. In the case of a SIB the outcome payor would be the domestic government, for example the UK Government for a UK based programme, but also the Ghanaian Government for a Ghana based progamme. In contrast, for a DIB, the outcome based payor is external to the country in which the programme is being executed, for example, the UK funding a results-based outcome in Ghana.

It can be argued that DIBs evolved from IDA buydowns of the World Bank and the bilateral Debt2Health Swaps pioneered by the German and Australian governments between 2004 and 2008. Under these programmes, a developing country debt was written off if a developing country achieved certain development objectives.

The term "Impact Investment" was coined by the Rockefeller Foundation in 2007. The sector has built substantial momentum, with both institutional and more socially focused investors dedicating capital to this sector. However as a concept, impact investment or mission related investment as it is sometimes called has a long history. The concept is perhaps most established in the United States. In 1969 thanks to the sponsorship of the Ford Foundation the concept of a "Programme Related Investment" (PRI) was developed for US Foundations enabling them to count "impact investments" against their $5 \%$ annual payout obligations. In fact, PRIs themselves were not a new concept but can be traced back to the eighteenth century when Benjamin Franklin used financial instruments for artisan and humanitarian organisations3). In the last twenty years the quantum of US PRI's has grown to $\$ 5.2 \mathrm{bn} 4)$.

3) Leveraging the Power of Foundations: An Analysis of Program-Related Investing, Lilly Family School of Philanthropy 2013. (http://www.philanthropy.iupui.edu/files/ research/complete_report_final_51713.pdf)

4) Ibid. Refers to total PRI Dollar Amount 1990-2010, using data from The Foundation Centre, The PRI Directory 
It is important to note that while DIBS/SIBs represent a new paradigm in bringing investment to areas of social development that have historically been the domain of grant or public programmes, the concept of "finance" has a long history in development. Building on the foundations of Bretton Woods institutions from the 1940's, the concept of a country entering into a loan to finance development is well established. In 1960 the World Bank first developed IDA as a concessional window that would lend to the least developed nations on very long dated terms to compliment traditional bilateral grant funding.

제I장

제II장

The IDA model is a success story with the majority of countries progressing through the system and many graduating to full MDB lending terms. Notable examples include both the Republic of Korea and China. However for a number of African nations the capital provided by IDA was not used to drive productive investment, but rather to finance a burgeoning current account deficit. For these countries the burden of debt became unsustainable at the turn of the Century and as a result of public pressure and donor commitment, agreement was reached in 2005 at the G8 Summit in London to write off the entire US\$40 billion debt owed by the 18 heavily indebted poor countries to
Development Impact Bonds "Modelled on Social Impact Bonds (SIBs), which are already being implemented in many countries across the world from the UK to Australia, Development Impact Bonds (DIBs) are a new financing instrument that can help bring together the diversity of players involved in today's development scene, and use the best resources and expertise each player can offer to improve the quality and efficiency of social programmes and maximise social impact. As with a SIB, investors provide funds to implement social interventions, service providers work to deliver outcomes, and outcome funders, primarily public sector agencies, repay investors their principal plus a financial return if - and only if - independently verified evidence shows that outcomes have been achieved. A distinguishing feature of DIBs is that external development agencies would normally be needed to provide the outcome payment, or some portion of it in partnership with a developing country government; DIBs are therefore a tool which can improve both the efficiency of public services in developing countries and the efficiency of donor spending."

Investing in Social Outcomes: Development Impact Bonds October 2013 
the World bank, the IMF and the African Development Fund5). This followed a previous G-8 summit agreement to write off much of the outstanding bilateral developing country debt in 1999.

The debt write downs of 2000-2005 were catalytic in a number of ways, restoring financial balance to the African continent in particular and allowing counties to invest in their own development. We believe that this action to cleanse the balance sheets of the developing nations has been the biggest driver of development since 2000, stabilizing currencies which in turn has attracted investment and fueled development. The commodities super cycle has also helped, given the rich commodity endowment of many developing countries, but these countries would not have been able to leverage the cycle without attracting investment, which would not have occurred without the stabilization in foreign currency cashflow that came from the multilateral debt relief (MDR) programme of 2005 .

The Government of Germany took the MDR to a new dimension, reviewing their portfolio of bilateral loans and offering certain governments the option to have the loan cancelled in exchange for meeting certain development objectives. In 2008 Germany executed the first Debt2Health swap with Indonesia. Under this structure in exchange for a cancellation of $€ 50$ million of their bilateral debt to the Government of Germany, Government of Indonesia agreed to meet a defined set of development objectives including investing half of that amount into health programs to fight HIV/AIDS, tuberculosis and malaria. Subsequent transactions included Germany to Pakistan, Germany to Cote d'Ivoire and Australia to Indonesia. Debt2Health Swaps formed one of the three pillars of innovative finance for health in the early 2000's which also included long term donor commitments in the form of the International Finance Facility for Immunisation

5) IMF and World Bank Debt Relief Under the Heavily Indebted Poor Countries (HIPC) Initiative https://www.imf.org/external/np/exr/facts/hipc.htm 
(IFFIm) and development focused taxes in the form of the air ticket tax levy (UNITAID).

The Debt2Health swap model differs from a DIB in that the debt had been incurred at an earlier point in time and the proceeds had not been earmarked to achieve the purpose for which the buy-down had been agreed. This is less controversial as it may seem as many of the most intractable challenges in developing countries require local currency financing (to pay wages etc). Therefore if the cancellation of a foreign debt by a foreign party catalyses a domestic government to repiroritise its budget to achieve certain defined development objectives, then significant benefit can be achieved.

Under a parallel system to the debt swap, in 2003/4 the British Government and the Bill \& Melinda Gates Foundation, a buy-down was agreed for IDA loans to both Nigeria and Pakistan upon successful completion of a polio eradication program. In this example, the countries entered the IDA loan in full knowledge of the buydown agreement and outcome payors, in contrast to the Debt2Health swaps, where the debt had been incurred for a different purpose, typically many years earlier. For this reason, arguably, the IDA buydowns were the first DIBs. 


\section{World Bank "Buy Down" models:}

Loan buy downs have been deployed in a number of instances to incentivize and finance development outcomes. There are two basic structures: buy downs that convert loans to grants and buy downs that make loans more concessional.

Loan to Grant:

These buy downs are structured such that a third party pays down the principal of an outstanding loan on behalf of the borrower. In Nigeria and Pakistan, BMGF paid off the entire value of IDA credits of approximately $\$ 140 \mathrm{~m}$ for each country over the course of 2004 to present. The actual amount paid by BMGF was much less than $\$ 280 m$ - instead it was the net present value discounted against the term of the credit as well as the risk associated - for example, the total budgeted allocation for Nigeria is \$9om.

Concessional loans

These buy downs are structured such that the Third Party, Donor and Recipient coordinated to reduce the terms of the loan. This model has been deployed by UK Department for International Development (DfID) in China for three \$10om IBRD loans. As China graduated from IDA loans, DfID used the buy down to make a small number of higher cost IBRD loans concessional in order to incentivize rural public sector education and health investment. DfID paid $\$ 105 \mathrm{~m}$ to effectively reduce the interest rate paid by China to IBRD to $2 \%$. These payments were not linked to results - but the funding was targeted to specific social sector development activities.

The IDA Buy downs differ from a classic DIB/SIB structure in that the borrower remains obligated to payback the loan regardless of whether or not the outcome is achieved. This is an important distinction and may be a key feature that differentiates how or whether DIBs do truly scale.

It should be noted that the largest sector that combines both impact investment with outcome based finance currently is the Carbon Market using a range of feed-in tariffs and renewables obligation certificates. While there have been many challenges with the schemes, not least the failure to secure a global commitment to the reduction in $\mathrm{CO}_{2}$ emissions, the system has reached scale and offers many lessons for the DIB market. Designed to improve the efficiency 
of carbon usage to avert the worst impact of climate change, at its core, this sector offers the best example of how Government Policy and the provision of outcomes based payments can lead to the deployment of billions of dollars of private sector capital, seeking both a financial and a social return.

Critically the carbon market demonstrates that when a clear objective is defined, billions of capital can be activated in an area that was previously viewed as non-economic. We believe that this is the most important precedent for the DIB, because of the scale reached and the fact that it catalyzed substantial investment in developing nations. In 2008 the European Union agreed to allow certain specific non-EU verified carbon credits to enter the EU market under the Clean Development Mechanism (CDM) system. This system offered a results based payment stream to projects that could demonstrate reductions in carbon dioxide emissions. Securing a verified carbon credit entailed a significant friction costs for the project originator and the financial benefit was of variable value as it relied on the trading price of $\mathrm{CO}_{2}$ on the European market at the point of delivery, many years forward, with no forward market to allow contracts to be hedged. However despite these uncertainties by 2012 the CDM Board had issued 1 billion CERS, 60\% of which originated from projects in China, only ceasing in 2013 with the collapse of the carbon price in Europe and the failure of the US to implement a national carbon pricing scheme.

Unless DIBs can scale to the range of hundreds of millions or even billions they will be of limited developmental value. This point was endorsed in the Zedillo report of 20016). Ernest Zedillo, the former finance Minister of Mexico was challenged with the task of estimating the increased Overseas Development Assistance (ODA) spend necessary to meet the Millennium Development Goals in 2015. Zedillo estimated that it would require an additional \$40obn of investment

6) United Nations (2001), Report of the High Level Panel on Financing for Development (http://www.un.org/en/ga/search/view_doc.asp?symbol=A/55/1000) 
from the donor nations to achieve these goals. Whilst donor capital flows have not achieved this goal, the gap has been taken up by the private sector. The flows of FDI into developing nations totaled US\$1.45 trillion in 20137), surpassing that of developed nations for the first time in 2012. It can be seen therefore that unless DIBs are able to scale to billions of US dollars equivalents in size to be of any long term value to development.

In combining the scale of "giants" such as IDA and the CDM market it can be seen that the opportunity exists for results based development impact bonds to operate at a scale that would indeed result in a meaningful development benefit.

\section{Current State of the Development Impact Bond Market}

\section{“Mighty Oaks From Small Acorns Grow" Geoffrey Chaucer 1374}

The first Development Impact Bond in name was launched in June 2014 in the Education sector. Designed by Instiglio, a DIB specialist advisor in the US, this Education DIB brings together a leading NGO in India - Educate Girls, and two Foundations - The Children's Investment Fund Foundation (based in the UK) and the UBS Optimus Foundation (based in Switzerland)8).

"In India, 3.7 million girls are out of school. In Rajasthan, 40 percent of girls drop out before reaching fifth grade and for those that remain learning quality is low. Only 15 percent of children in primary school can read a simple story in Hindi. Uneducated girls in India are three times more likely to contract HIV, earn 10 percent less income, and marry three years earlier than educated ones." Instiglio

7) UNCTAD (2014) World Investment Report (http://unctad.org/en/PublicationsLibrary /wir2014_en.pdf)

8) News Release: Investing for social outcomes: CIFF and UBS Optimus Foundation launch the first development impact bond in education http://www.instiglio.org /pub/EG_DIB_Press_Release.pdf 
Under the model US\$238,000 is being provided to Educate Girls to expand their services in Rajasthan from UBS Optimus. The NGO will work with approximately 150 schools and is targeting to reach 10,000 girls, with the objective of substantially reducing the prevailing drop-out rate. If the established targets are met, CIFF will repay UBS Optimus' investment. While the initial amount is small, the intention is that this will serve as a pilot which can be scaled up both in India and internationally. The challenge of girls not completing basic education is a global issue and yet it provides the most powerful driver to lift a family and ultimately a country out of poverty. Donor backed Government programmes that simply create school places have universally failed to address the issue due to cultural and social factors which enforce the status quo. Commencing its work in 2007 Educate Girls sought to address this issue by outreach to the parents of Girls, development of school improvement plans to make schools more girl friendly (simple interventions such as the provision of drinking water or a separate girls toilet facility which can be the reason that girls drop out, but SIPs are parent led and hence address the specific needs of their school). Educate Girls has developed an improved learning programme which has been shown to increase learning outcomes on all metrics. Finally through their "Bal Sabhas", Girls Counsels, Girls are trained in life skills to improve their future potential and to serve as mentors in their community to ensure the development progress is permanent. In 6 years of operation, Educate Girls has reached over 500,000 children, catalyzed the re-enrollment of 57,000 girls and trained over 6,500 girls in their Bal Sabhas programme. Currently only operational in Government schools in three districts of Rajasthan, the ambition is to spread their programme to all of Rajasthan and subsequently throughout India.

The new DIB structure to expand Educate Girls proven programs achieves a number of aims. UBS Optimus Foundation brings together the investor clients of UBS, who see their capital have a catalytic effect, but value the fact that their capital can will be returned in the event of success to enable re-deployment. 
This is a way to attract much more capital into the sector. For CIFF, they are guaranteed that they will only make the payment in the event that the programme has worked. Although at the smallest end of scale for a development intervention, there is an interest from all parties to scale the programme up if it is indeed as successful as intended.

Education represents a very fertile sector for DIBs. In 2012, Lion's Head Global Partners performed a comprehensive review of the Low Cost Private School sector in Pakistan, home to the largest number of out of school children in the World. The low cost private schools (LCPS) have arisen from the population bulge currently to be found in Pakistan and the inability of the Government via state funding to create sufficient places for these children under their free school programme. Often started by a single teacher in a small room, LCPS operate on a daily fee basis, with a cost of roughly $\$ 50$ per year per child. These schools now educate approximately $25 \%$ of all children in Pakistan. Strikingly similar school programmes have been identified in all developing countries and in both the poorest communities, which are rarely reached by Government programmes and in more developed areas, where parents place a premium on the quality of education. Importantly the schools are financially self-sustaining, but are most effective when a certain size of school has been reached. Ideally there should be sufficient class rooms to teach different years separately. However this requires investment capital. In Punjab State of Pakistan, the Punjab Education Fund provides loans to schools to expand their facilities. They also provide results based payments to the schools if education targets are achieved. The programme could be further scaled and offers tremendous potential for a DIB structure due to the well-established baselines and governance infrastructure that has been developed over the past 22 years. 


\section{Punjab Education Foundation (PEF)}

Established in 1991 as an autonomous statutory body to encourage and promote education in the private sector, the PEF receives money from the Punjab Government and the World Bank and DfID for its programmes.

Through its Foundation Assisted Schools (FAS) programme, schools are given student subsidies of PKR350 - PKR400 for primary and secondary school students on the condition that they offer free education to all students \& that they achieve a minimum student pass rate of $67 \%$ on the Quality Assurance Tests (QAT). Bonuses are awarded to teachers and schools with the highest pass rates, as further incentive to improve the quality of the education they provide. This programme currently assists over 10,000 schools, reaching approx $1,400,000$ students of whom $50 \%$ are girls. A World Bank impact assessment of the programme suggested it is one of the cheapest programmes for increasing enrolment in the developing world.

Through its Education Voucher Scheme (EVS), children aged 4-17 years from poorest families to get free education in the nearest (PEF EVS) private schools of their own choice. In March 2008 it had enrolled 10,000 low-income students in 52 private schools.

PEF supported schools have seen significant increases in the number of students and schooling inputs, improved gender ratios and low dropout rates.

\section{DIB to target Sleeping Sickness in Uganda}

In April 2014 the British Department for International Development announced that it intended to launch a DIB to support the treatment of cattle in Uganda to reduce the burden of sleeping sickness. This is of particular urgency in Uganda as Uganda is the only country in the world to have both the Rhodesian and the Gambian forms of African sleeping sickness. Currently the two forms are geographically divided, but there are substantial public health concerns that should cattle become infected with both sets of parasites a new more virulent form of the disease could develop. The disease burden is on the rise with the migration of cattle (reservoir hosts for sleeping sickness) throughout the country. Cost effective, preventative measures to reduce the disease burden through mass treatment of cattle have been developed and piloted and requires investment 
capital for scale-up. The DIB structuring is still in development phase, but UK DfID has committed $11.5 \mathrm{~mm}$ to the programme, which if successful would lead to a further scaling up of the programme.

\section{The Future of Development Impact Bonds}

"The future starts today, not tomorrow." Pope John Paul II

The Development Impact Bond working group in its report of October 20139) identified a further 4 case studies for DIBs. In the areas of Education (secondary education in Uganda), Global Health (HIV treatment in Swaziland, Malaria treatment in Mozambique), Economic Development (SME support) and Climate Change (investment in energy efficiency improvements). However it was very clear from the groups work, that this can be applied to multiple different areas of development.

\section{Opportunities for Korea International Cooperation Agency}

It can be seen that the areas being considered for DIBs have strong overlaps with many of the core areas of focus for KOICA. Climate Change, Education, Environment, Industry and Energy, Health and the MDGs more broadly. These are all areas where programmes requiring upfront capital can be identified and where an outcome based payment stream could be defined based on specific results. However, programmes could be designed in the case of Governance, Agriculture, Forestry and Fisheries, ICT and disaster relief. These are considered in turn below

9) http://www.cgdev.org/publication/investing-social-outcomes-development-impact-bonds 


\section{Governance}

Historically Governance has been one of the most challenging sectors in terms of results. Corruption is an endemic feature in almost all developing countries. Furthermore impact is generally secondary, as a result of improvements in other sectors such as Education, Industry and ICT. However some key foundations have established programmes that seek to address this issue in innovative ways in which to address this issues which could represent opportunities for a DIB. The Ibrahim Foundation, established by the entrepreneur Mo Ibrahim, seeks to specifically catalyse improvements in governance of African leaders. The Foundation offers a personal prize for "Good Governance" to African leaders acting as a carrot to encourage them to pass on power democratically. A DIB could be structured alongside the Ibrahim Foundation to enable Governance training for deeper layers of a country's leadership to assist with the routing out of mal-practice.

The Institute for Economics and Peace has created an innovative index - The Peace Index, which tracks progress of countries to development through an index of the absence of conflict. They evaluate both high income and low income countries alike. Sponsored by the philanthropy of Steve Killelea, a successful Australian Tech entrepreneur. A DIB could be created that was linked to certain improvements in a country, or region's standing in the Peace Index.

\section{Agriculture Forestry and Fisheries}

This is an area which represents many opportunities for results based programmes and one or more DIBs.

In Agriculture, there is a pressing need for better establishment of new seed varieties or improved farming techniques to increase yields and reduce the climate impact of different interventions. The CGIAR represents 16 Research 
groups whose focus is the development of improved products for agriculture, forestry and fisheries. Without this work, the planet will not be able to sustain its projected population of 9 billion. However this work is of limited value if it simply remains in the laboratory. The CGIAR is moving to a more results based focus and working with donors like KOICA would be willing to structure a DIB that was targeted at the roll-out of successfully produced new products.

Other areas for consideration include results based payments for improvements to fishing stocks. Programmes can be designed to support fisherman to improve their fishing practices to generate less wastage and enable key sporning grounds to recover. A DIB could be established where payment was linked to the outcome, with NGOs and other groups managing the implementation on the ground.

Chocolate demand continues to grow as the World population grows and wealth becomes more balanced. However the locations in the World where chocolate can be grown at high yields are limited. The existing chocolate plantations need to be replaced with higher yielding trees, but farmers have limited incentives to do so. This is both a financing and an implementation challenge. Cocoa Trees take upto 3 years to become productive, farmers therefore need financing to bridge the gap while the new trees grow. There is also a technical skill required to teach farmers how to graft on new trees onto existing tree roots to enhance yields, but without destroying existing tree root infrastructure. A DIB could be established alongside the food industry which has a strong interest in increasing the annual supply of Cocoa.

\section{ICT}

ICT is increasingly the backbone for all of society in developed countries. This risks creating a greater gap with developing countries and their economic growth. However as we have seen due to the absence of much traditional 
infrastructure, developing countries are very rapid adopters of new technology. The speed with which the mobile phone has been adopted in developing countries is a perfect example. However if ICT is to really deliver a dividend for economic development there is a need for it to be integrated into all key sectors of KOICA's strategy. This is however especially true in the case of results based programmes, as generally it is the use of ICT that enables the results to be monitored, often for the first time. We see particular opportunities for ICT in the area of health, education, climate change and governance (especially tax collection). Each of these could represent an opportunity for a DIB.

제I장

제I장

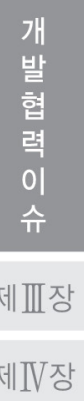

Particular opportunities include translation of existing products for use in a developing country setting, expansion of broadband networks to rural areas and supporting the roll-out of low cost "smart" devices. Korea has the benefit of a very strong history in ICT and world leading companies that can play a role with KOICA in a DIB in this area.

\section{Disaster Relief}

Disaster Relief is not normally associated with a results based programme. It generally being the opposite - a bad result. However increasingly we are seeing that natural disasters are increasing in their frequency as a result of climate change. There is therefore an urgent need to focus on programmes that build resilience and support communities impacted by adverse weather events. Programmes such as weather insurance offer almost the inverse of a DIB. Here a payment is made if there is a negative outcome. However by putting such programmes in place, assistance can be accelerated to an impacted area and incentives are then in place for communities to protect against future disasters through improved building programmes and community planning. These programmes are critical if the population is to survive without mass migration in a World where climate change will be uneven in the distribution of its impact. 


\section{Are DIBs the answer to all development issues?}

Sadly DIBs are not the magic bullet for development. However they do represent a valuable new tool in the armory of development funders to achieve positive social outcomes. However, there are many instances where a DIB is not the ideal development and tool and a DIB structure could add friction to a currently efficient system of procurement. Furthermore we find that a DIB will only offer value if there has been genuine risk transfer. A private sector investor will be unwilling to take Government performance risk, if there is not a clear set of policies supporting the programme. However if participation requires the de-risking of a programme entirely, then traditional finance from multilateral development organisations or DFIs will be more cost effective.

DIBs are attractive when they offer a way to create an incentive for multiple actors to drive a particular change. This can be seen in low cost private schools, where the schools are individually run, but the programme offers a way for each to participate if they are willing to agree to a common set of goals. Similarly Health DIBs would work well in Africa where over $50 \%$ of the health service provision is given by private sector operators and thus national hospital programmes are often unable to achieve country wide impact, due to the fact that there is not universal coverage. Encouragement should be taken from the Carbon sector, which while currently somewhat subdued, has led to the mobilization of billions of dollars of investment by non-state actors, catalyzed by clear market signals from the Public Policy. 
Increasingly we see the donor community under pressure to offer better evidence of the outcomes of their ODA budgets vs the outputs ${ }^{10)}$. Programmes such as the Grand Challenges, established by the Bill \& Melinda Gates Foundation and groups such as Grand Challenges Canada offer outcome based payment streams. The World Bank has a Results Based Trust Fund, dedicated to the development of outcome based payments, benefiting from support from a broad range of donors including Australia, Canada, Germany, Netherlands, Norway and UK. But in almost all circumstances the outcome requires upfront investment. This is the role for the DIB - to bridge the gap between the upfront capital required and the outcome based payor at the end. In this regard, the potential for DIBS is arguably much stronger than for SIBs, as there is already capital dedicated to making outcome based payments and the sector has benefited from many years of intense research to identify areas well suited to outcome based funding and those that are not. The fact that a body of research into development results-based financing was completed before the concept of a DIB was ever conceived is both a positive and a negative. The positive is that researchers have not been biased by a desire to create viable DIB structures. The negative is that many results- based models were abandoned due to the absence of an upfront funding stream. There is therefore significant value to be obtained by revisiting the work of the past 15 years on Results Based Payments in light of the new DIB developments to assess which areas would indeed represent the most fertile opportunities.

Finally we would note that all results based systems including DIBs have the potential to create perverse incentives. In the main, the primary objectives will be unquestionable, however often secondary negative externalities can develop which can lead to mistrust in the system. Therefore it is critically important for

10) Organization for economic co-operation and development (OECD 2005/2008): Paris declaration on aid effectiveness and the Accra agenda for action http://www.oecd.org/dac/effectiveness/parisdeclarationandaccraagendaforaction.htm 
all DIB structures to leverage highly respected partners, who have the experience of the local situation in which they are working and the capacity to adapt a programme to prevent unintended consequences.

In conclusion, we welcome the evolution of the Development Impact Bond instrument to fill an unmet need where there is genuine risk transfer and shortage of capital to scale-up effective social programs. In a connected world where aid effectiveness is emphasized, the DIB structure facilitates transparency of shared benefits between new capital providers (investors), payors, implementers and ultimately, program beneficiaries. The DIB structure is not ideal for all development initiatives and there needs to be tandem creation of independent monitoring and evaluation work of social outcomes alongside every DIB project. Following the world's first DIB launched in June 2014, we forsee rapid pilots of additional programs, but success lies in proving the model, matching risk and reward and reaching sustainable scale. 